In using the term "flowering", Williams presumably refers to anthesis. So far as Gregory's results for barley are concerned, he claimed only that net assimilation rate was independent of time up to maximum leaf area, that is, for about the first six weeks, which corresponds with the stage of first differentiation of the flowers, not anthesis. After this point he also noted a rapid fall in net assimilation rate. For only one of the two experiments on oats described by Williams ${ }^{2}$ does he appear to have obtainefd "unit leaf rate" data before six weeks, and in this case the rate appears to be remarkably constant up to 4-6 weeks. In so far as the cited experiments with temperate cereals are concerned, the results thus appear to confirm Gregory's findings. In the case of the single experiment with Sudan grass $^{3}$, the unit leaf rate appears to fall from the first observation (two weeks). It would be interesting to know the time of differentiation of flowers in this species.

The further interpretation of the data will be awaited with interest.

O. V. S. Heath.

Research Institute of Plant Physiology, Imperial College of Science and Technology, London, S.W.7. Jan. 17.

${ }^{1}$ Williams, R. F., NATURE, 140, 1099 (Dec. 25, 1937).

2 Williams, R. F., Austral. J. Exp. Biol., 14, 165 (1936).

3 Ballard, L. A. T., and Petrie, A. H. K., Austral. J. Exp. Biol. 14, 135 (1936).

Heath, O. V. S., Ann. Bot., N.S., 1, 565 (1937).

- Gregory, F. G., Ann. Bot., 40, 1 (1926).

- Crowther, F., Ann. Bot., 48, 877 (1934).

' Portsmouth, G. B., Ann. Bot., N.s., 1, 277 (1937).

\section{Blindness in Freshwater Fishes}

The cause of blindness in some rainbow trout was recently described by $\mathrm{me}^{1}$ as being due to a trematode, Diplostomum volvens Nord., being present in large numbers in the lens of the eye. Since that date, two more lots of rainbow trout and one lot of roach have been examined, and in each case about five per cent of the fish were blind, due to a similar cause to that already recorded.

I have also been informed from a reliable source that the disease is well known in Holland and other countries of Europe. Further, my attention has been directed by the Hon. Miss M. Rothschild to further literature of the subject, particularly to a recent account of this trematode by Wesenberg-Lund in his work on freshwater fauna ${ }^{2}$ which records that Diplostomum volvens Nord. does not possess a direct life-cycle from bird to fish but that the fertilized eggs, which pass out of a water bird, develop into a miracidium which penetrates a molluscan and there produces the asexual cycle generation of sporocysts. These in turn give rise to fork-tailed cercariæ, which in due course escape from the snail or first intermediate host into the water. It is at this stage that the worm enters the second intermediate host.

The cercariæ penetrate the skin of the fish and reach the lens of the eye via the blood stream; the final host invariably acquires the parasite by eating fish which have become infected in this way.

Biological Department,

WitfRId RUSHTON.

\section{St. Thomas's Hospital Medical School,} London, S.E.1. Jan. 19.

1 NATURE, 140, 1014 (Dec. 11, 1937).

" "Ferskvandsfaunaen, Biologiste Belyst", Invertebrata, vol. 1. Trematoda-iken, pp. 123-127, Fig. 135-140;' 1937.

\section{Density of Living Aquatic Organisms}

For some reason, the determination of the density of aquatic organisms has always presented to biologists a really difficult problem. The usual method has been to kill or narcotize the organisms and find the rate at which they sank in a liquid of known density, or alternatively to find a liquid of such density that the organisms floated or rather just did not sink in it. The density of the liquid was taken as the density of the organism. Neither of these methods need, I think, be seriously considered further. They may be suitable for minerals but scarcely for living organisms.

There is a very simple and accurate method available and this is best described by giving an actual example. Three typical specimens of the common polychæte worm Nereis diversicolor were sent from Plymouth in a large jar of sea-water. They arrived in perfect condition. The jar was placed in a sink of cold water until the temperature was constant. A specific gravity bottle was cleaned, weighed and standardized. The bottle was then weighed full of distilled water at $7 \cdot 4^{\circ} \mathrm{C}$., which was the temperature of the water in the sink. It was then filled with the sea-water and weighed, and finally the three worms were introduced and the bottle again weighed.

The only remaining problem was then to find the exact volume of the worms. This was quite readily done by pouring the contents of the bottle after the last weighing into a $200 \mathrm{ml}$. flask. The worms were retained in a funnel with a small plug of glass wool. When practically all the sea-water had gone the worms were just rinsed with a little distilled water. (If this is thought objectionable a little isotonic solution of sodium nitrate could have been substituted, but actually this was quite unnecessary since the worms went straight back to sea-water and were alive after two days.) They were only in contact with the distilled water for a few seconds. The solution of sea-water in the $200 \mathrm{ml}$. flask was made up to the proper mark. We can call this solution $A$.

The same specific gravity bottle was then again filled with the sea-water and the contents washed into another $200 \mathrm{ml}$. flask. We can call this solution $B$. The two solutions have different concentrations which can be determined by a very simple titration with $N / 10$ silver nitrate, which incidentally need be only approximately $N / 10$. From these two titrations the exact volume of the worms is obtained. The accompanying figures give the density of Nereis fairly exactly. The last two figures should probably be disregarded since the density of Nereis must vary with such factors as the contents of the gut, etc., or the sex. Again, it represents the average density of the three worms. Finally, densities given to six places of decimals are meaningless unless the density of the distilled water has been redetermined since the discovery of heavy water.

Volume of S.G. bottle at $20^{\circ} \mathrm{C}$. and $760 \mathrm{~mm}$. $51 \cdot 21 \mathrm{ml}$.

Weight of distilled water at $7 \cdot 4^{\circ} \mathrm{C}$. $51 \cdot 4198 \mathrm{gm}$

$$
\text { " sea ", ", } 52.8384 \text {, }
$$$$
\text { " ", sea-water plus Nereis at } 7 \cdot 4^{\circ} \mathrm{C} \text {. } 53 \cdot 0733 \text {," }
$$

Calculated density of sea-water at $7 \cdot 4^{\circ} \mathrm{C}$. $\quad 1.02766$ Volume of Nereis. Titrations with silver nitrate $N / 10: 14.35 \mathrm{ml}$. ;
$12.91 \mathrm{ml}$.

$$
\text { Vol. }=51 \cdot 21-\left(\frac{12 \cdot 91}{14 \cdot 35} \times 51 \cdot 21\right)=5 \cdot 14 \mathrm{ml} .
$$

Weight of sea-water displaced by Nereis $=5.14 \times 1.02708$ ,$\quad$ in bottle with $"=52 \cdot 8384-5 \cdot 2822=47.5562$
" $"$ " Density of Nereis at $7 \cdot 4^{\circ} \mathrm{C} .=\frac{5 \cdot 5171}{5 \cdot 14}=1 \cdot 07336$. 